\title{
The Robust Analysis of Examination and Approval Process Based on Markov Chain
}

\author{
Fan Bo* \\ School of Economics and Management \\ Beijing Jiaotong University \\ Beijing, China \\ 19891016fanfan@163.com \\ *Corresponding author \\ Li Ma \\ School of Economics and Management \\ Beijing Jiaotong University \\ Beijing, China \\ Mail.f116@gmail.com
}

\author{
Yihong $\mathrm{Ru}$ \\ School of Economics and Management \\ Beijing Jiaotong University \\ Beijing, China \\ yhru@bjtu.edu.cn
}

\begin{abstract}
The international trade volume has increased in a large scale in recent decades, the efficiency and effectiveness of the examination and approve process have been playing a more and more important role within it. However, the current study in this area is little and some studies only consider the alone agent and they don't put all the related agents in the examination and approve process into a whole one. Therefore, in this paper we use the Markov chain to analyze the service level of the whole examination and approval process and apply the robust theory to compute the stability and reliability of the process in a further way.
\end{abstract}

Keywords- examination and approval process; Markov chain; robust analysis

\section{INTRODUCTION}

The operation of examination and approval process has its own special characteristics, such as the requirements of high speed operating time and the best assignments accuracy. Therefore, it's significant for us to put more efforts on the management and optimization of the examination and approval process. At the moment, the number of research on the examination and approval process is few, so we could only list some of these articles to illustrate the current research status on it.

Wang,M.Z. and Zhang,J. (2009) discussed the examination and approval flow technology of CAPP system and they introduced how to use the userinfo database to realize examination and approval flow in CPPS. Zhao,Zhongming and Zha,Run (2011) have a study on the optimization of one-stop electronic procedures of examination and approval. In this paper the authors put forth an one-stop model after the optimization and recreation of the existing administrative procedures by systematic reform method.

According to the above descriptions, most of current studies in examination and approval process are focused on the reform policies, but the analysis from the perspective of supply chain management is very little. So in this paper, we apply the thought of supply chain management to regard the examination and approval process as a supply chain. As we all know, the uncertainty is obvious in the supply chain and so is the examination and approval process, So in this paper we use the method of Markov chain to illustrate the random and uncertainty of the process.

Luo, Jian-Qiang and Zhao, Yan-Ping (2010) put a research on the supply chain product market forecasting based on Markov chain. They used the method of statistical forecast analysis of random phenomena and built a forecast Markov model about the occupancy rate of market. Yin, Xiangzhou et.al (2010) used Markov chain to analyze the stability of closed-loop supply chain. They get the long-term stable cooperation mode in the closed-loop supply chain at the end of the paper.

But what we should do to deal with the uncertainty in the process is an important question which has been discussed frequently nowadays. Robust is the quality of retaining the capacity of the chain when it comes across some sudden affairs. So we can apply the theory of robust to analyze the examination and approval process to ensure its stability and reliability of operation in the long run.

Lou, Catherine Xiaocui et.al (2012) put forward the robust supply chain services system through optimization modeling. This research proposes a novel robust enterprise supply chain services framework that considers risk and financial management in corporations' governance. Yan, Ni-Nal et.al (2010) wrote a paper called "Robust optimization of multisourcing strategies in resilient supply chain". In this paper, they establish a resilient supply chain system. The absolute robust problems, robust deviation problems and relative robust problems are solved respectively. Li et.al (2010) studied the development of a robust supply chain for dynamic operating environment. It discusses the development of tools and 
concepts towards effectively managing the purchasing and supply chain function.

This article is organized as follows. In Sec. 2, we describe the problem which appears in the examination and approval process. The theory of Markov chain is used in Sec. 3 to analyze the service capacity of the whole process. The robust analysis method is discussed and we use it to calculate the stability and reliability of the process in Sec. 4 , followed by a conclusion in Sec. 5.

\section{PROBLEM FORMULATION}

\section{A. The background description}

The ultimate goal of the examination and approval operation is to make sure the goods can go into and out of the border smoothly with the least time and the highest accuracy. But at the same time, we must consider that there are many uncertainty factors which exist in the process. For instance, the operation time at each node in the chain is various and uncertain. Besides, the strategies which every agent will choose are different with each other either. All of these elements may influence the process operation which in turn leads to the uncertainty in the chain.

Therefore, the task for us is to analyze the stability of the process which could be shown by the service capacity and level under the uncertain environment. In a further way, we must consider what should we do to ensure the normal operation if the uncertain affairs appear in the process. That is to say, we should also analyze the reliability of the chain and to take effective measures.

\section{B. The process model}

The examination and approval process is conducted by different agents, such as the consignor, the involved governments like agriculture and health ministry, the bureau of inspection and quarantine, the custom and so on. The three echelon of process design model is proposed in this paper which is contained by four agents, the consignor, the health ministry, the inspection and quarantine bureau and the custom.

So according to the above discussion, we construct the examination and approval process model and we can see it from figure 1 .

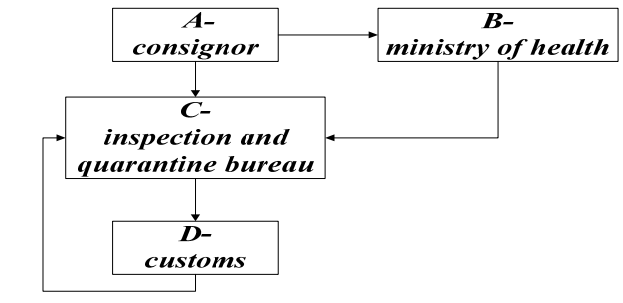

FIGURE I. THE MODEL OF THE EXAMINATION AND APPROVAL PROCESS

\section{The theory usability}

\section{1) Assumptions in the process model}

There are many assumption conditions in the process model and we can list them as follows:
(1) The choosing principle of every node is that it must be the best choice in the whole examination and approval process not in the single point.

(2) Choosing various strategies can lead to different probabilities in the operation time.

(3) The k-th node's strategy depends on the previous k-1 nodes' strategies and it has no connection with other nodes' strategies.

(4) $\mathrm{T}$ is a random variable and it confers to the dispersed distribution.

According to all the assumptions above, it meets all the requirements and characteristics of the Markov chain, so we can use the theory of Markov chain to make a deeper analysis in the following section 3 .

\section{THE SERVICE CAPACITY ANALYSIS BASED ON MARKOV CHAIN}

\section{A. The analysis steps in the process model}

Step one: Assume the operation time of the first node is $\mathrm{T} 1=\left\{T_{1}{ }^{(1)}, T_{1}{ }^{(2)}, \ldots, T_{1}{ }^{(q)}\right\}$, the probability distribution is $P=\left\{T_{1}=T_{1}{ }^{(1)}\right\}, P=\left\{T_{1}=T_{1}{ }^{(2)}\right\}, \ldots, P=\left\{T_{1}=T_{1}{ }^{(q)}\right\}$, and at the same time $\sum_{j=1}^{q} P\left\{T_{1}=T_{1}{ }^{(i)}\right\}=1 \quad$. Because $C_{1}=T_{1} \quad$ so $C_{1}=\left\{T_{1}{ }^{(1)}, T_{1}{ }^{(2)}, \ldots, T_{1}{ }^{(q)}\right\}$.In other words, we can describe it like this: let $C_{1}^{(j)}=T_{1}^{(j)}$, so we can conclude that $P\left\{C_{1}=C_{1}{ }^{(j)}\right\}=P\left\{T_{1}=T_{1}{ }^{(j)}\right\}, j=1,2, \ldots, q$

Step two: The operation time of the first $\mathrm{k}$ nodes are $C_{K}, C_{K}=\left\{C_{K}^{(1)}, C_{K}{ }^{(2)}, \ldots, C_{K}{ }^{(u)}\right\}$, the probability distribution is $P\left\{C_{K}=C_{K}^{(j)}\right\}$. So we can get the one step transfer matrix from $C_{K}$ to $C_{k+1}$.

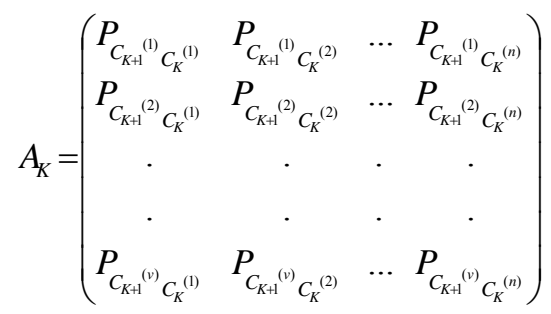

The meaning of the equation $P_{C_{K+1}^{(i)} C_{K}^{(j)}}=P\left\{C_{K+1}=C_{K+1}{ }^{(i)} \mid C_{K}=C_{K}{ }^{(j)}\right\}$ is: under the condition of the first k nodes' operation time is $C_{K}=C_{K}{ }^{(j)}$, the probability of the first $\mathrm{k}+1$ nodes' operation time is $C_{K+1}=C_{K+1}{ }^{(i)}$.In a further way, because $C_{K+1}=C_{K}+T_{K+1}$, so $C_{K+1}{ }^{(i)}=C_{K}{ }^{(j)}+T_{K+1}{ }^{(i)}$, and we can conclude that $\quad P_{C_{K+1}^{(i)} C_{K}^{(j)}}=P_{T_{K+1}^{(i)} C_{K}^{(j)}}$,we can also get $P\left(C_{K+1}^{(s)}\right)=\sum\left\{P_{T_{K+1}^{(j)} C_{K}^{(j)}} \bullet P\left\{C_{K}=C_{K}^{(j)}\right\}\right\}$ eventually.

Step three: Through a series of this kind of computes, we can get the probability distribution of the examination and approval process on the operation time $\left\{P\left(C_{N}{ }^{(1)}\right), \ldots, P\left(C_{N}{ }^{(w)}\right)\right\}$. 
And the expectation value of the whole operation time is $E\left(C_{N}\right)=\sum_{i=1}^{w} C_{N}{ }^{(i)} \bullet P\left(C_{N}^{(i)}\right)$

\section{B. The service capacity analysis of the process model}

\section{1) The strategies used in the process model}

Now, we can make the following table to describe the strategies which the agents could choose during the process. In the table, we can learn the information such as the time that has been spent in themselves, the alternative strategies for agents to choose and the corresponding probabilities. We can see it from Table.1.

TABLE I. THE TABLE OF THE STRATEGIES IN THE PROCESS UNDER THE WHOLE CHAIN

\begin{tabular}{|c|c|c|c|c|}
\hline node & A & B & & $\mathrm{C}$ \\
\hline $\begin{array}{c}\text { The days has spent } \\
\text { when it gets the } \\
\text { node }\end{array}$ & 0 & 12 & 12 & 345 \\
\hline $\begin{array}{c}\text { The choosing } \\
\text { strategies of every } \\
\text { agent }\end{array}$ & (1) & (2) (3) & (4) (5) & (6) (7) (8) \\
\hline $\begin{array}{l}\text { The days has spent } \\
\text { in this code }\end{array}$ & 12 & 2323 & 3434 & 343434 \\
\hline $\begin{array}{l}\text { Probability } \\
\text { distribution }\end{array}$ & 0.40 .6 & $\begin{array}{c}0.70 .3 \quad \\
0.4 \\
0.6\end{array}$ & $\begin{array}{c}0.40 .60 .3 \\
0.7\end{array}$ & $\begin{array}{c}0.70 .30 .60 .4 \\
0.50 .5\end{array}$ \\
\hline & \multicolumn{4}{|c|}{$\mathrm{D}$} \\
\hline & & 5 & 7 & 9 \\
\hline & & (9) (10) & 1) (12) (13) & (13) (14) \\
\hline & 1 & $212 \quad 12 \quad 12$ & 12 & 212 \\
\hline
\end{tabular}

Notes: The number (1)(3) (12) is the best strategy for every agent in the process.

We must point out that the node $\mathrm{C}$ faces two different types of operation situations. That is to say, if A needn't to receive the inspection from $\mathrm{B}$, then the time where gets to $\mathrm{C}$ is one or two days and the probability of this situation is 0.3 . But on the other hand, if A must accept the B's inspection, then the time where gets to $\mathrm{C}$ is three, four or five and the probability is 0.7 .

\section{2) The computation test of the process model}

We can consider the node A, B, C, D as the members to make up a main chain, which can be known as the examination and approval process. We will analyze it by the echelons in the chain.

\section{a) The strategy choice from the whole process} perspective

The total time in the node $\mathrm{A}$ is $C_{1}=\{1,2\}$, the probability is $\{0.4,0.6\}$; The total time to get $\mathrm{B}$ is $C_{2}=\{3,4,5\}$, the probability is $\{0.28,0.36,0.36\}$.

The computation procedure is as follows: the probability of 3 days is $0.4 \times 0.7=0.28$, the probability of 4 days is $0.4 \times 0.3+0.6 \times 0.4=0.36$, the probability of 5 days is $0.6 \times 0.6=0.36$.
The situation of $\mathrm{C}$ is a little complex, the whole potential time of $\mathrm{C}$ is $C_{3}=\{4,5,6,7,8,9\}$ and the probability is $\{0.048,0.126,0.2632,0.21,0.2268,0.126\}$. We only take the days of 5 and 6 as examples to illustrate the computation procedure.

5days:

$$
0.3(0.4 \times 0.6+0.6 \times 0.3)=0.126
$$

6days: $0.3 \times 0.6 \times 0.7+0.7 \times 0.28 \times 0.7=0.2632$.

The total time in the node $\mathrm{D}$ is $C_{4}=\{5,6,7,8,9,10,11\}$ and the probability $\{0.0144,0.084,0.12824,0.31556,0.26376,0.14364,0.0504\}$.

Until now, we can achieve the service capacity of the process if the time which has been spent of 7,8 or 9 days. The compute procedure is $0.12824+0.31556+0.26376=0.70756$. And the service level can be said at $70.756 \%$.

\section{b) The strategy choice from the single node perspective}

At this situation, the nodes in the process will choose strategies from their own point of view rather than consider the whole chain.

So now we will compute the service level under the strategy of (1)(3) (8) . And we may remade the table of the strategies used in the process at Table2.

TABLE II. THE TABLE OF THE STRATEGIES IN THE PROCESS UNDER IN THE SINGLE NODE

\begin{tabular}{|c|c|c|c|c|}
\hline node & A & B & C & D \\
\hline $\begin{array}{c}\text { The days has spent when it gets } \\
\text { the node }\end{array}$ & 0 & 12 & 345 & $\begin{array}{c}678 \\
9\end{array}$ \\
\hline $\begin{array}{c}\text { The choosing strategies of every } \\
\text { agent }\end{array}$ & 1 & (3) & 8 & (12) \\
\hline The days has spent in this code & 12 & 23 & 34 & 12 \\
\hline Probability distribution & $\begin{array}{ccc}\mathbf{0 . 4} \\
\mathbf{4}\end{array}$ & $\begin{array}{c}\mathbf{0 . 6} \\
\mathbf{0 . 6}\end{array}$ & $\begin{array}{c}\mathbf{0 . 5} \\
\mathbf{0 . 5}\end{array}$ & $\begin{array}{c}\mathbf{0 . 5} \\
\mathbf{0 . 5}\end{array}$ \\
\hline
\end{tabular}

The time in the last step is $C_{4}^{\prime}=\{7,8,9,10,11\}$ and the probability is $\{0.04,0.2,0.37,0.3,0.09\}$.

So the service level at 7,8 or 9 days is $0.04+0.2+0.37=0.61$, that is to say the service capacity is at $61 \%$. When we compare this number to the above result of $70.756 \%$, we may discover some conclusions which will be summed up in the next part.

\section{THE ROBUSTNESS ANALYSIS IN THE PROCESS}

\section{A. The base data and numerical testing}

The base case is constructed, which is shown in the following figure2.In this figure, the first number in the bracket means the robustness of the node or line and the second number means the time has been spent in this node or line.

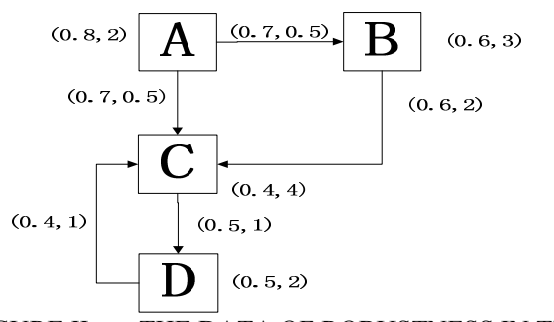

FIGURE II. THE DATA OF ROBUSTNESS IN THE EXAMINATION AND APPROVAL PROCESS 
Now, we can use the above method and formulation

(1) to compute the robustness of the process.

$R=[0.8 \bullet(0.7 \times 0.6 \times 0.6+0.7) \bullet 0.4 \times 0.5 \times 0.5 \times 0.4] \bullet \min \left(\frac{8}{\max \left(\begin{array}{c}2+0.5+3+2+4+1+2+1 \\ 2+0.5+4+1+2+1\end{array}\right)}, 1\right\}=0.0157$

B. The analysis of robustness in the process

Due to the uncertainty in the examination and approval process will appear at any time, so we must analyze the process when it comes across the outburst events.

1) The various service capacities in node $A|C| D$

TABLE III. THE TABLE OF THE ROBUSTNESS OF A $\backslash$ C $\mid D$ IN VARIOUS SERVICE CAPACITIES

\begin{tabular}{|c|c|c|c|}
\hline $\begin{array}{c}\text { Service } \\
\text { capacity in } \\
\text { various nodes }\end{array}$ & $\begin{array}{c}\text { Robustness } \\
\text { of transfer } \\
\text { lines }\end{array}$ & $\begin{array}{c}\text { Time radio of } \\
\text { meeting } \\
\text { demands }\end{array}$ & $\mathbf{R}$ \\
\hline $10 \%$ & 0.0030464 & 0.516129032 & 0.001572 \\
\hline $20 \%$ & 0.0060928 & 0.516129032 & 0.003145 \\
\hline $30 \%$ & 0.0091392 & 0.516129032 & 0.004717 \\
\hline $40 \%$ & 0.0121856 & 0.516129032 & 0.006289 \\
\hline $50 \%$ & 0.015232 & 0.516129032 & 0.007862 \\
\hline $60 \%$ & 0.0182784 & 0.516129032 & 0.009434 \\
\hline $70 \%$ & 0.0213248 & 0.516129032 & 0.011006 \\
\hline $80 \%$ & 0.0243712 & 0.516129032 & 0.012579 \\
\hline $90 \%$ & 0.0274176 & 0.516129032 & 0.014151 \\
\hline $100 \%$ & 0.030464 & 0.516129032 & 0.015723 \\
\hline
\end{tabular}

From table3, we can learn that robustness of the process will increase with the increase of the service capacity.

2) The various service capacities in node $A|C| D$

TABLE IV. THE TABLE OF THE ROBUSTNESS OF B IN VARIOUS SERVICE CAPACITIES

\begin{tabular}{|c|c|c|c|}
\hline $\begin{array}{l}\text { service } \\
\text { capacity in } \\
\text { various nodes }\end{array}$ & $\begin{array}{l}\text { Robustness } \\
\text { of transfer } \\
\text { lines }\end{array}$ & $\begin{array}{l}\text { Time radio of } \\
\text { meeting } \\
\text { demands }\end{array}$ & $\mathbf{R}$ \\
\hline $10 \%$ & 0.0232064 & 0.516129032 & 0.011977 \\
\hline $20 \%$ & 0.0240128 & 0.516129032 & 0.012394 \\
\hline $30 \%$ & 0.0248192 & 0.516129032 & 0.01281 \\
\hline $40 \%$ & 0.0256256 & 0.516129032 & 0.013226 \\
\hline $50 \%$ & 0.026432 & 0.516129032 & 0.013642 \\
\hline $60 \%$ & 0.0272384 & 0.516129032 & 0.014059 \\
\hline $70 \%$ & 0.0280448 & 0.516129032 & 0.014475 \\
\hline $80 \%$ & 0.0288512 & 0.516129032 & 0.014891 \\
\hline $90 \%$ & 0.0296576 & 0.516129032 & 0.015307 \\
\hline $100 \%$ & 0.030464 & 0.516129032 & 0.015723 \\
\hline
\end{tabular}

From table4, we can also learn that robustness of the process will increase with the increase of the service capacity.

\section{3) The various service capacities in node $A|C| D$ and $B$}

We can compare the robustness of node $A \backslash C \backslash D$ with $B$ under different service capacities and we can see it from the figure3.

From the figure3, we can learn that the speed of robustness increase in node $A \backslash C \backslash D$ is much faster than in $B$ and the line of node $B$ is always on ahead of $A \backslash C \backslash D$. That is to say, the robustness of node B makes up most part in the whole process and it plays an important role in the operation procedure.

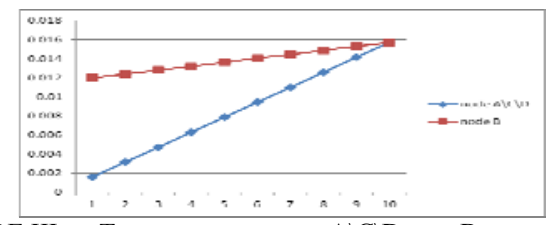

FIGURE III. THE ROBUSTNESS OF A\C\D AND B IN THE PROCESS

\section{CONCLUSION}

In this paper, we apply two main theories to analyze the examination and approval process, they are the Markov chain and Robustness.

Firstly, we use the method of Markov chain to compute the service capacity of the whole chain and we compare it with the best strategy choose in single node. So we get the conclusion that the service level by considering the whole chain is higher than by thinking the single point.

Secondly, we use the robustness to compute the reliability of the process. According to the results, we may know that the robustness of the whole chain depends largely on the node B, so we can pay more attention on the node B to achieve the best performance in the examination and approval process.

\section{ACKNOWLEDGMENT}

This paper was funded by the Administrative Committee of Zhongguancun Science Park Foundation and the project group of "Discuss of Import and Export Circulated Supervision Model and Platform Construction for Biological Reagents at Zhongguancun", and all support is gratefully acknowledged.

\section{REFERENCES}

[1] Gabriela P. Ribasa,b, Silvio Hamacherb and Alexandre Streeta: Optimization under uncertainty of the integrated oil supply chain using stochastic and robust programming. Intl. Trans. in Op. Res. 17 (2010) 777-796.

[2] J Aharon Ben-Tal a, Byung Do Chung b, Supreet Reddy Mandala, Tao Yao: Robust optimization for emergency logistics planning: Risk mitigation in humanitarian relief supply chains. Transportation Research Part B 45 (2011) 1177-118.

[3] Feng Pan,RakeshNagi: Robust supply chain design under uncertain demand in agile manufacturing. Computers \&Operations Research 37(2010)668-683.

[4] G.J. Hahn,H.Kuhn: Value-based performance and risk management in supply chains:A robust optimization approach. Int. J.Production Economics 139(2012)135-144.

[5] Hal Caswell: Sensitivity analysis of discrete Markov chains via matrix calculus.Linear Algebra and its Applications 438 (2013) 1727-1745.

[6] Gary H. Chao: Production and availability policies through the Markov Decision Process and myopic methods for contractual and selective orders. European Journal of Operational Research 225 (2013) 383-392M.

[7] Atefeh Baghalian a, Shabnam Rezapour c, Reza Zanjirani Farahani: Robust supply chain network design with service level against disruptions and demand uncertainties: A real-life case.European Journal of Operational Research 227 (2013) 199-215.

[8] Xuan Huang, Nuo Xu and Soren Bisgaard: A Class of Markov Chain Models for Average Run Length Computations for Auto correlated Processes.Communications in Statistics-Simulation and Computation R, 42: 1495-1513, 20 